\title{
Strengthening Doctoral Programs in Mathematics Education: A Continuous
} Process

\section{Barbara Reys and Robert Reys}

Editor's note: An article "Math PhD Careers..." in the March Notices described a model program preparing young mathematicians for a broader range of careers. The article "Disruptions of the Academic Math Employment Market" appeared in the October 2016 Notices.

ABSTRACT. We offer some ideas for improving doctoral preparation based on a survey of faculty members from twenty-three different institutions.

There have been many calls to examine doctoral preparation in the United States [1], [2]. These calls have been initiated by professional organizations and by the Carnegie Foundation and have led to timely and practical suggestions for change [3], [4]. The Carnegie Foundation initiative addresses a wide range of disciplines, including doctoral preparation in mathematics and education [5].

From 2010 to 2014, 129 different institutions in the United States produced at least one doctoral graduate in mathematics education [6]. These institutions differ greatly in the number of faculty in mathematics education, the number of full-time doctoral students, the number and types of doctoral courses and experiences offered, and the institutional resources available to support doctoral candidates [7].

The purpose of this article is not to detail the content of any specific doctoral program in mathematics education, but to offer some ideas regarding improvement efforts from a recent survey of twenty-three institutions. ${ }^{1}$ Over

Barbara Reys is Curators' Distinguished Professor Emerita of Mathematics Education at the University of Missouri-Columbia. Her e-mail address is ReysB@mi ssouri . edu.

Robert Reys is Curators' Distinguished Professor Emeritus of Mathematics Education at the University of Missouri-Columbia. His e-mail address is ReysR@mi ssouri . edu.

For permission to reprint this article, please contact: reprint-permission@ams .org.

DOI: http://dx.doi.org/10.1090/noti1499 the past fifteen years these institutions have been involved in improving their doctoral programs in mathematics education with support from the Centers for Learning and Teaching (CLT) initiative of the National Science Foundation. Faculty members at the CLT institutions were asked to identify unique features of their doctoral preparation that might be of interest to faculty members involved in doctoral preparation at other institutions. This article provides a summary of their responses.

Each CLT institution was engaged in improving its doctoral preparation (in quality and quantity). While these efforts clearly led to an increase in the number of graduates [6], the extent to which particular features improved the quality of graduates (in terms of impact on the field) is much harder to document. Anecdotal evidence suggests that many of the CLT doctoral graduates are conducting research and publishing their work in high-impact research journals at a higher rate than is typical of early-career graduates. However, more systematic attention is needed to document trends. In this article we summarize some unique features of the CLT doctoral programs that survey respondents believe set their programs apart and likely

${ }^{1}$ City University of New York, Michigan State University, Ohio University, Penn State University, Rutgers University, University of Arizona, University of California-Berkeley, University of California-Los Angeles, University of California-Santa Cruz, University of Delaware, University of Georgia, University of Illinois-Chicago, University of Kentucky, University of Louisville, University of Maryland, University of Michigan, University of Missouri, University of New Mexico, University of Pennsylvania, University of Tennessee, University of Wisconsin, West Virginia University, and Western Michigan University. 
increase the quality and productivity of graduates. These features are grouped around four themes.

Theme 1. Establishing and articulating the nature, content, and specific expectations of the doctoral program. Given the uniqueness of most doctoral programs in mathematics education, it is essential to make public to prospective and current students the specific program requirements. This can be done through a variety of means, including a handbook, website, and/or induction seminars.

- Some institutions touted the number of mathematics education courses (as many as eight) available for doctoral students, including courses focusing on mathematics assesment, mathematics curriculum, mathematics teaching, learning mathematics, and technology in mathematics education.

- Some institutions offer unique pathways toward a doctorate in mathematics education. One program is completely personalized, requiring only two one-credit courses, with the remainder determined by the student's committee in collaboration with the student. Other programs are designed to integrate mathematics education into other disciplines, such as intersecting mathematics with language and culture. Of the integrated programs, STEM was the most frequently cited pathway, although the composition of STEM programs and the extent to which mathematics education is reflected varied greatly. Each of the integrated programs touted the opportunities to work with outstanding faculty members representing a variety of disciplines.

- Some institutions reported a special focus/theme embedded within their doctoral program. Examples included: urban education, rural education, social justice/ equity/diversity, mathematics curriculum, and mathematics teaching. Establishing and promoting such specialty niches is consistent with the recommendation for creating intellectual communities that would allow doctoral students to choose institutions aligned with their particular interests [8]. Several institutions focus on preparing collegiate teachers of mathematics. These doctoral programs are housed in mathematics departments and require a substantial amount of graduate-level work in mathematics.

Theme 2. Aggressively recruiting doctoral candidates. Obtaining a steady stream of new, high-quality doctoral students is an essential component in shaping and improving programs. Strategies for identifying and attracting potential candidates that some institutions have used successfully include:

- Recruiting through word of mouth by alumni (i.e., asking alumni to be ambassadors for their doctoral program).

- Advertising in professional journals and booths at professional meetings to alert people to their doctoral program.

- Conducting a letter-writing campaign every year to colleges and universities within the region that do not have doctoral programs in mathematics education, encouraging faculty to invite and direct their best students with interests in mathematics education to consider entering their doctoral program.

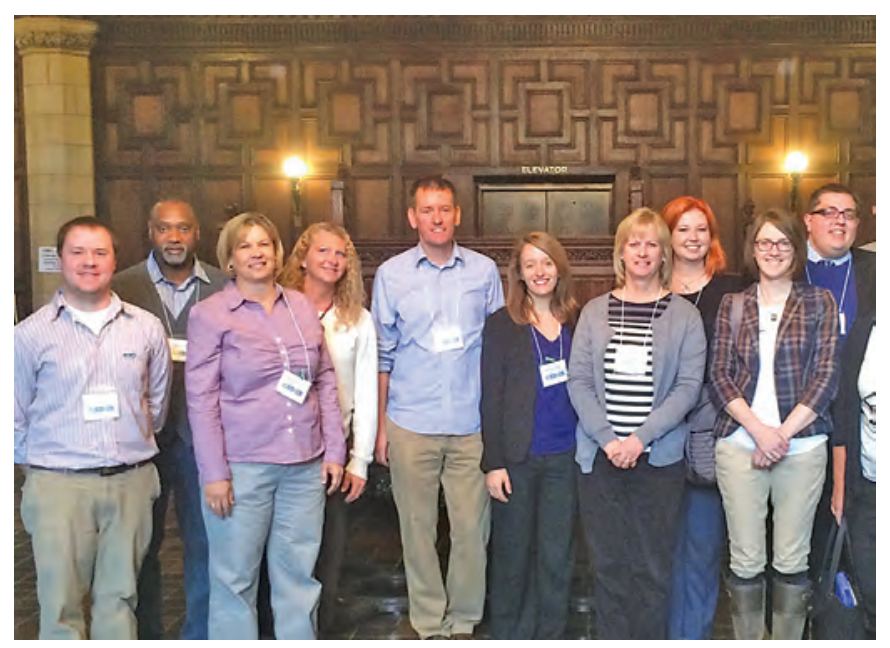

Participants in the Third International Center for the Study of Mathematics Curriculum Conference on Mathematics Curriculum at the University of Chicago in 2014 (left to right, showing graduating institution and current employment): Chris Engledowl (University of Missouri, current doctoral student), Nevels Nevels (University of Missouri, Hazlewood School District), Dawn Teuscher (University of Missouri, Brigham Young University), Karen Fonkert (Western Michigan University, Charleston Southern University), Shannon Dingman (University of Missouri, University of Arkansas), Nicole Fonger (Western Michigan University, postdoc at University of Wisconsin), Becky Darrough (University of Missouri, Austin Peay University), Amanda Thomas (University of Missouri, University of Nebraska), Lorraine Males (Michigan State University, University of Nebraska), A. J. Edson (Western Michigan University, Michigan State University).

- Contacting local school districts to recruit experienced mathematics teachers, including a specific effort to recruit urban and rural mathematics teachers who may not have considered entering a doctoral program.

Once strong candidates are identified, strategies are utilized to help them make a commitment to doctoral preparation, including:

- Talking with prospective candidates and highlighting the job opportunities along with the shortages of doctorates in mathematics education for faculty positions in institutions of higher education.

- Providing information about financial support available to them (scholarships, fellowships, assistantships, and fringe benefits, such as medical insurance, travel support, office space, and computers).

- Inviting the top-rated applicants to campus for oneor two-day visits. This costs between $\$ 500$ and $\$ 1,000$ per candidate and has served as an excellent investment of resources. These visits provide an opportunity for the potential applicant to meet and engage in conversations with faculty and learn about current interests and research opportunities. The applicants also meet with current doctoral students so they learn about the culture and environment 
of the mathematics education program. Only a limited number of new doctoral students can be supported each year, and these visits allow wise decisions as to which of the applicants should be awarded the largest scholarships and most prodigious fellowships.

Theme 3. Establishing a professional community that includes doctoral students. It is important to help new students acclimate to the doctoral program and also to provide continuous opportunities for every doctoral student to bond and grow and interact with a community of professionals including faculty, staff, and other doctoral students throughout the doctoral program. Strategies to establish and nurture such a community include:

- Organizing a seminar for first-year doctoral students to help them acclimate to their new environment, learn about institutional resources (library, health center, etc.), and get acquainted with faculty members and become knowledgeable about some of their expertise.

- Arranging for every student to be involved in a research study that must be completed by the end of the second year. This early immersion in research is facilitated by faculty-run research groups in an apprenticeship mode. This active engagement in research may be done independently or in a cohort, but the research study or studies are monitored by a faculty member regularly involved in the doctoral program.

- Scheduling a weekly seminar that doctoral students participate in throughout their program. Every doctoral student must make at least two presentations in a weekly seminar. Their presentations may take different

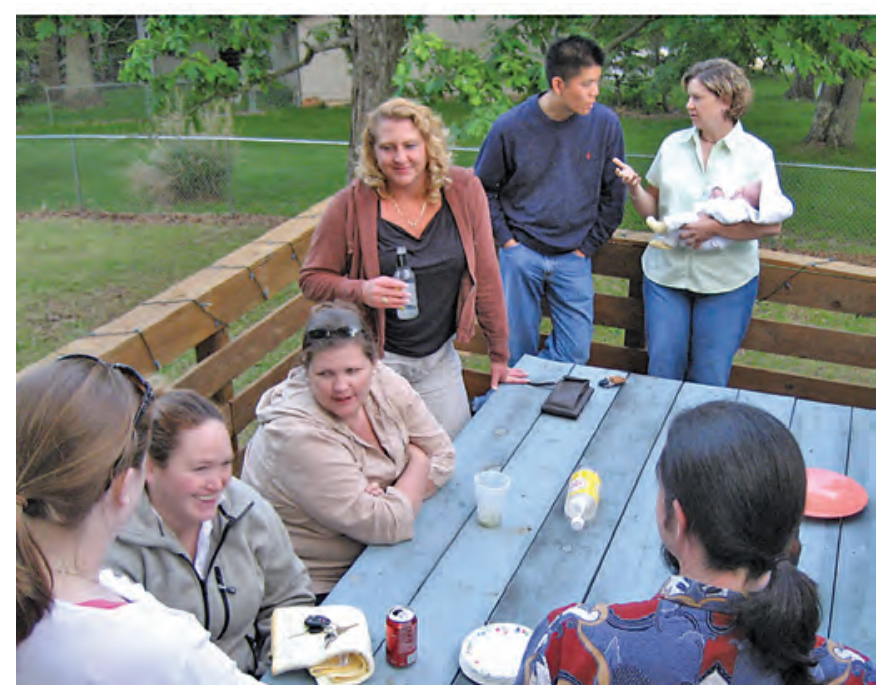

Enjoying a barbecue during a CSMC Research

Conference in 2007 (left to right, showing graduating institution and current employment): Amanda Thomas (University of Missouri, University of Nebraska); Eileen Olson, spouse of Travis Olson (University of Missouri, UNLV); Jill Newton (Michigan State University,

Purdue University); Karen Fonkert (Western Michigan University, Charleston Southern University), Jeff Shih (UCLA, UNLV); Dawn Teuscher (University of Missouri, Brigham Young University); Ryan Nivens (University of Missouri, Eastern Tennessee University). forms, such as soliciting suggestions for a potential research project, providing a report of research in progress, sharing a draft of a manuscript being prepared for publication consideration, or highlighting a research presentation that has been or will be made at a professional meeting.

Theme 4. Preparing for a career in higher education. Regardless of the research emphasis of an institution, teaching is a common expectation of mathematics educators entering positions in higher education. Another widespread need is preparing proposals for funding. Strategies used to support this preparation include:

- Improving instruction by having doctoral students serve as teaching assistants (TAs) within undergraduate or graduate $\mathrm{K}-12$ teacher preparation courses. As part of these assistantships, they meet regularly (e.g., weekly) with other TAs and faculty to share challenges faced in the classes they are teaching and to discuss research-based evidence to improve their collective practice [9], [10]. At some institutions, TAs teach from a common set of shared, detailed lesson plans and meet weekly to debrief and to plan for the following week. Everyone is engaged in research and development that aims to improve the lessons and the overall learning and teaching of mathematics. This teach-research-teach model provides an algorithm for doctoral graduates to continue to reflect upon and improve their teaching throughout their careers.

- Giving students first-hand experience in preparing grant proposals. Doctoral students are engaged in preparing at least one proposal for funding. This may include, but is not limited to, searching for appropriate funding agencies, securing proposal guidelines, and conceptualizing a study, as well as writing and critically reviewing drafts of a proposal. In some cases, it has provided opportunities for faculty members and doctoral students to visit funding agencies to meet and talk with program officers about forthcoming proposals.

Where to from here? A major takeaway from the survey of CLT doctoral programs in mathematics education is that continual review and improvement is critical to growth in both quantity and quality. This article is an effort to share suggestions that might be useful in developing and improving doctoral preparation. While the focus has been on mathematics education, it is certainly possible that some of these suggestions are generic and would be of interest to mathematicians involved in $\mathrm{PhD}$ programs in mathematics.

One message from the Carnegie Foundation efforts is that doctoral programs need to be examined and reviewed regularly [3]. It could be argued that a doctoral program 


\section{COMMUNICATION}

should be critically examined every five to ten years. If it has not changed during that time, then it is probably time to make some changes. Toward that end, it is our hope that some grist from this paper will be useful to doctoral faculty members looking for fresh ideas to strengthen their doctoral programs.

ACKNOWLEDGMENT. Research for this article was funded by the National Science Foundation under grant No. 1434442. However, the opinions expressed are the authors' and do not reflect any endorsement by the National Science Foundation.

References

[1] W. JAmES, The PhD octopus, Harvard Monthly 50 (1903), 149-15.

[2] A. JACKSON, Should doctoral education change? Notices Amer. Math. Soc. 43 (1996), no. 1, 19-23.

[3] Association of Mathematics Teacher Education (AMTE). Principles to Guide the Design and Implementation of Doctoral Programs in Mathematics Education, AMTE, San Diego, CA, 2003.

[4] C. M. GOLDE and G. E. WALKER (eds.), Envisioning the future of doctoral education: Preparing stewards of the discipline, Jossey-Bass, San Francisco, CA, 2006.

[5] H. BASS, Developing scholars and professionals: The case of mathematics, in C. Golde and G. Walker (eds.), Envisioning the future of doctoral education: Preparing stewards of the discipline, Jossey-Bass, San Francisco, CA, 2006, pp. 101-119.

[6] B. REYS and R. REYS, A recent history of the production of doctorates in mathematics education, Notices Amer. Math. Soc. 63 (2016), no. 8, 936-939.

[7] R. E. Reys, R. Glasgow, D. Teuscher, and N. Nevels, Doctoral programs in mathematics education in the United States: 2007 status report, Notices Amer. Math. Soc. 54 (2007), no. 11, 1283-1293.

[8] J. Hiebert, D. LAmbdin, and S. Williams, Reflecting on the conference and looking toward the future, in R. Reys and J. Dossey (eds.), US Doctorates in Mathematics Education: Developing Stewards of the Discipline, American Mathematical Society/Mathematical Association of America Washington, DC, 2008, pp. 241-252.

[9] L. B. Flick, P. SADRi, P. D. Morrell, C. WAinwright, and A. SCHEPIGE, A cross discipline study of reform teaching by university science and mathematics faculty, School Science and Mathematics 109 (2009), 197-211.

[10] R. REYS, Getting evidence based teaching practices into mathematics departments: Blueprint or fantasy? Notices Amer. Math. Soc. 60 (2013), no. 7, 906-910.

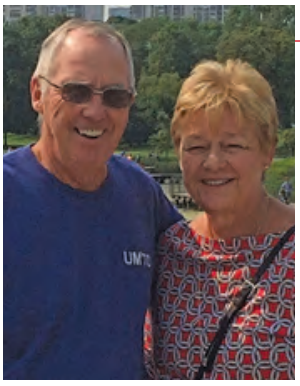

THE AUTHORS

Robert and

Barbara Reys

\section{Check Out the AMS Reviews Page Online!}

\section{Are you interested in popular books with mathematical themes?}

Then you'll enjoy the AMS Reviews Page, which offers links to reviews for hundreds of mathematically-related books, plays, films, and television shows.

\section{www.ams.org/reviews}

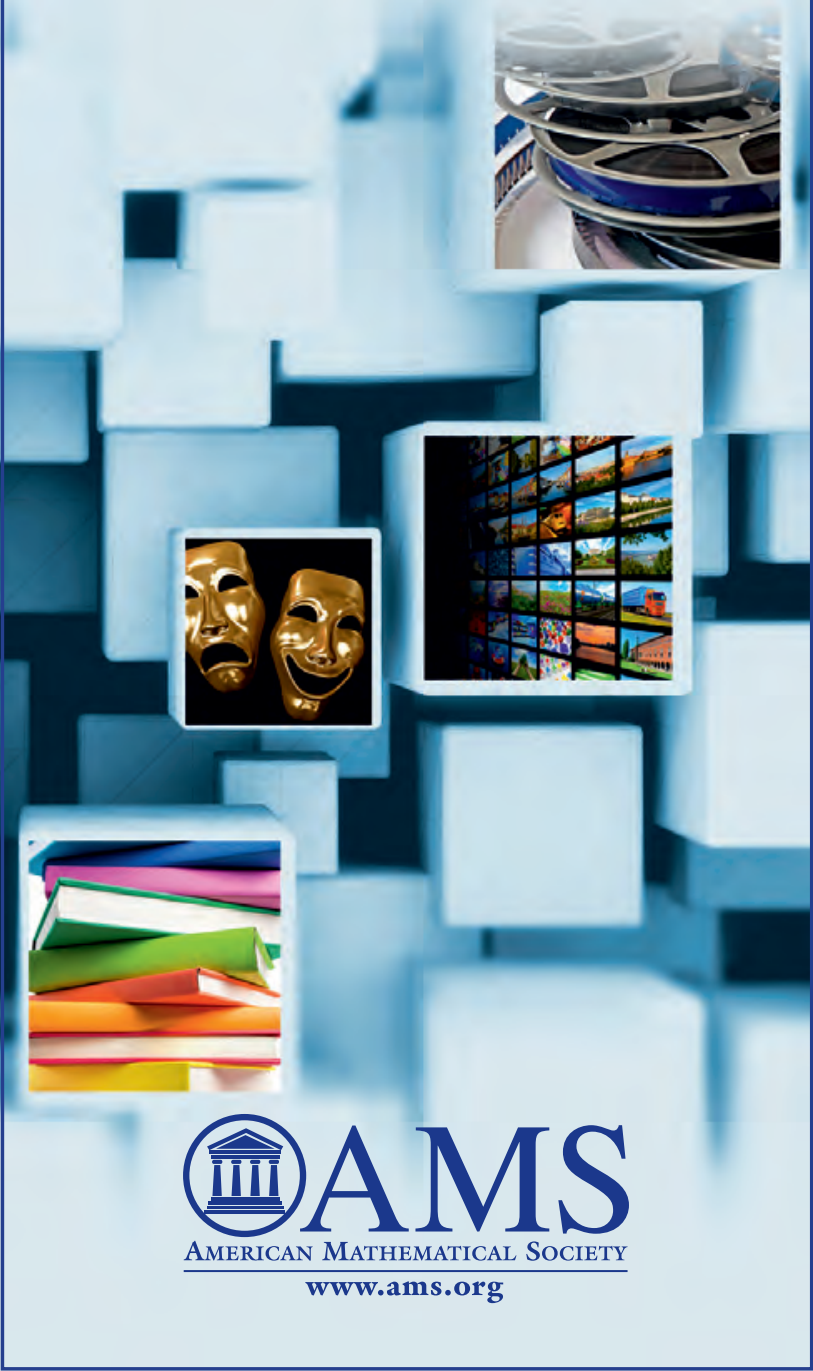

